\title{
Suicide risk: automated underwriting versus medical experts
}

\author{
n Cite as: CMAJ 2019 June 10;191:E640-1. doi: 10.1503/cmaj.181058
}

CMAJ Podcasts: author interview at https://soundcloud.com/cmajpodcasts/181058-medsoc

$n$ the early 20th century, the rating of higher risk, "substandard" applicants for life insurance was largely the purview of physicians known as medical directors of life insurance companies..$^{1,2}$ Medical directors from the United States and Canada met annually between 1889 and 1991 under the umbrella of the Association of Life Insurance Medical Directors of America to update their knowledge at a time of rapidly evolving medical technologies. The work of this association contributed to a standardized process called automated underwriting, in which paramedical workers gathered key information from insurance applicants over the telephone and then assigned a risk score to each application. This score was constantly refined and tested according to its predictive value. ${ }^{3,4}$ Applications were routinely crosschecked with the Medical Information Bureau, a shared industrial database that had kept track of all life insurance applicants (including those who had been turned down) since 1902. By the 1960s, when combined with carefully crafted exclusion clauses, automated underwriting had become so effective that it often supplanted medical directors.

One kind of risk assessment, however, seemed to require ongoing expert attention. Life insurance companies had long mistrusted any applicant with a history of mental illness, fearing they would commit suicide. Between 1952 and 1962, the Metropolitan Life Insurance Company reported that suicide was its fifth leading cause of death leading to a policy payout, and it was unclear how this risk could be managed more effectively. ${ }^{5}$ Suicide clauses, written since the 19th century,

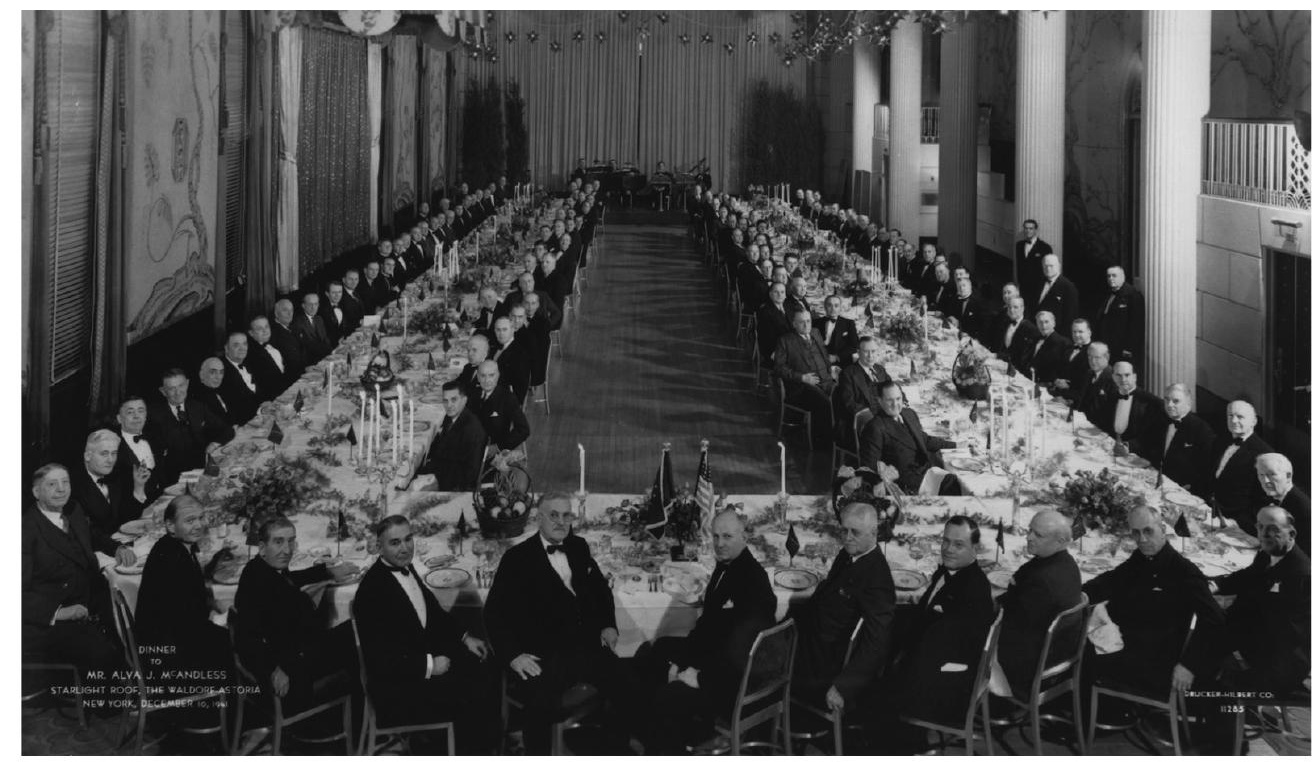

The 115 members of the Association of Life Insurance Medical Directors of America at their 1941 annual meeting in the Waldorf Astoria Hotel, New York City. Image courtesy of the American Academy of Life Insurance Medicine and the Katherine Shelby and Cullom Davis Insurance Library, New York.

had been proven hard to enforce, and screening questions were inadequate. ${ }^{6}$

Insurance companies in the first half of the 20th century built variables like sex, race and alcohol use into their models, and medical directors incorporated these variables into their risk assessments. ${ }^{7}$ Dr. Earl Dewey at the San Francisco office of Metropolitan Life, for example, was part of a generation of medical directors who believed that life insurance could be sold to housewives at a discount, because they were "shielded" from suicide by their husbands. ${ }^{5} \mathrm{He}$ also saw the "colored races" as "protected from the effects of suicide if they stayed in the south" even if "... migration north removed this protection because [they] ... apparently learn some of our ways of shuffling off our mortal coils."
Dr. Milton Clifford, medical director for the Union Central Life Insurance Company, focused on the effects of alcohol on suicide, encouraging his colleagues to uncover "the alcoholic of tomorrow." To find the future alcoholic, "... you had to catch him with his guard down," and Clifford kept informants including apartment janitors and priests. Like others of his generation, Clifford also looked to race, nationality and sex to spot riskier applicants. ${ }^{8}$ As Clifford explained, "... the rarity of alcoholism among Orthodox Jews and in the pure civilizations of Arabs and Chinese" portended better insurance risks than might be found among "the Irish," whom he took for granted as heavy drinkers and thus more likely to die by their own hand. ${ }^{8}$ 
In 1953, a year after the Diagnostic and Statistical Manual of Mental Disorders was introduced, Dr. Peter Denker, a psychiatrist at Cornell University, delivered a lecture to the medical directors of the life insurance association that promoted the value of clinical diagnosis in screening out the riskiest insurance applicants. ${ }^{9}$ By linking mortality data from the Equitable Life Insurance Company with coroners' reports, he suggested that companies could reduce payouts owing to suicide by $30 \%$ if they invested more in expert assessments. Relatively low rates of suicide, he thought, were associated with "psychoneurosis," which included "anxiety reactions," "neurasthenia," "hysteria" and "obsessive compulsive neurosis."

On the other hand, he cautioned insurers to steer clear of applicants with "psychopathic personality" and "psychosis." The real challenge for medical directors, he cautioned, was to uncover "hidden psychopathic personalities." Psychopathic personalities, which included "drug addicts, sexual perverts and alcoholics" were special cases that, he believed, would be missed by standardized screening questions. Here, Denker urged companies to pay for "examination by a competent psychiatrist." Applications pointing to "... vague or frequent illnesses" and those recording a "prolonged absence from work for so-called fatigue or exhaustion" were, in his view, high-risk files. Family history was also important because "genetic factors are being increasingly stressed." It was the role of experts above all to estimate “... the applicant's total personality, job record, marriage and social life, military record, draft board rejection and reactions to adversity." If necessary, "a full assessment would include talking to neighbors and fellow employees." ${ }^{\text {However, he was }}$ silent on the net financial costs and benefits of such intense assessments. This was the bigger picture for insurance companies, who quietly completed their own internal research, looking for hidden patterns in large numbers.

By the late 1960 s, more than $10 \%$ of life insurance applications were flagged with a psychiatric diagnosis, excessive substance use or both, and companies urgently needed to know how to assess this aspect of the market efficiently. Was diagnosis worth the cost of an expert assessment? An unusual yet efficient answer came from the John Hancock Mutual Life Insurance Company, where an internal audit between 1968 and 1974 looked at all causes of mortality across 3400 policies for which a psychiatric diagnosis was available. ${ }^{10}$ These policies had been issued after an initial telephone screen and, in some instances, a medical evaluation. Over six years, people categorized with schizophrenia and manic depression had a fatality rate of $0.5 \%$, whereas people with less severe forms of mental illness such as "psychoneurosis" had, perhaps as expected, a much lower fatality rate of $0.2 \%$. As Denker had predicted, those with "psychopathic personalities" had the highest death rate at $0.6 \%$.

However, death rates were only part of the story. Unexpectedly, although policyholders with psychiatric diagnoses died at 5-10 times the standard rate, the company payout rate was the same as it was for policyholders without any psychiatric designation. As it turned out, applicants with psychiatric diagnoses defaulted on their premiums at double the average rate. Furthermore, the auditors found that $90 \%$ of suicides occurred within three years of policy issuance. This offered auditors a way to feel confident managing the risk of payouts without going to the expense of expert assessments. An exclusionary period of three years coupled with existing screening techniques to filter applicants with a history of psychosis turned out to be the most cost-effective way to manage mental health risks. Suicide clauses had been used in the American life insurance industry since the 19th century, but the novelty of the John Hancock study was that it showed how a specific exclusionary period could be applied profitably.

After 1969, the Proceedings of the Association of Life Insurance Medical Directors of America no longer documented a pursuit of specific diagnostic subtyping in the field of mental medicine. Business logic dictated that existing screening techniques were adequate for the automated underwriting of mass-marketed, relatively low-value policies. The use of paid psychiatric consultants like Denker would be reserved for far more expensive "jumbo policies." For most applications for life insurance, fine-grained psychiatric diagnoses and the experts who made them became close to irrelevant to the bottom line. The Association of Life Insurance Medical Directors of America eventually folded into the American Academy of Insurance Medicine in 1991.

\section{Dorian Deshauer MD PhD}

Department of Psychiatry, University of Toronto, Toronto, Ont.

\section{References}

1. Porter T. Life insurance, medical testing, and the management of mortality. In: Daston L, editor. Biographies of scientific objects. Chicago: University of Chicago Press; 2000:226-46.

2. Bouk D. How our days became numbered: risk and the rise of the statistical individual. Chicago: University of Chicago Press; 2015.

3. Brown A. Excerpts from the history of ALIMDA. Proc Assoc Life Insur Med Dir Am 1989:208-18.

4. McAlister $\mathrm{CH}$. Underwriting the highly substandard risk. Trans Assoc Life Insur Med Dir Am 1950;24:132-42.

5. Dewey E. Suicides - a look at the statistics. Proc Assoc Life Insur Med Directors Am; 1963:54-69.

6. Blumenthal S. Law and the modern mind: consciousness and responsibility in American legal culture. Cambridge (MA): Harvard University Press; 2016.

7. Dublin L, Bunzel B. To be or not to be: a study of suicide. New York: Harrison Smith and Robert Haas; 1933.

8. Clifford M. Alcoholism: the search for the hidden alcoholic of today and of tomorrow. Proc Assoc Life Insur Med Dir Am 1960:14-36.

9. Denker PG. The evaluation and classification of neuropsychiatric disorders. Trans Assoc Life Insur Med Dir Am 1953-1954:37;142-55.

10. Garabedian G, Gajewski J, Richhart J. Approach to mortality studies of life insurance policyholders with psychiatric diagnoses. Trans Assoc Life Insur Med Dir Am 1976;60:241-51.

This article has been peer reviewed.

Disclaimer: Dorian Deshauer is an associate editor for CMAJ and was not involved in the editorial decision-making process for this article. 